Chapter 6

\title{
The Role of Earthquake Information Management System to Reduce Destruction in Disasters with Earthquake Approach
}

\author{
Sima Ajami \\ Additional information is available at the end of the chapter \\ http://dx.doi.org/10.5772/53612
}

\section{Introduction}

Iran, because of extent, geographical situation and climatic variety, is one of the disasterprone countries of the world. [1] Natural disasters, for example earthquake, are an unexpected event that cause damage and destruction to human life and health, and the injured persons without others assistance are not able to meet their need. Earthquakes in Iran and neighboring regions (e.g., India, Turkey and Afghanistan) are closely connected to their position within the geologically active Alpine-Himalayan belt (Table 1). [2-5] Earthquake crises disrupt all daily affairs of society, such as economic activities, city services, communication systems and community services and public health. [6] An Earthquake Information Management System (EIMS) is a system that records, collects, keeps, retrieves and analyzes inputs, produces reports and required earthquake information (EI) and renders them to the right people and organizations to manage earthquake response activities. [7] EI is not an end in itself, but it helps to make better decisions in designing policies, response planning, management of disasters, monitoring and evaluating disaster programs and services, and reducing damages. [8]

\section{Problem statement}

Unfortunately, information systems in most countries are inadequate to provide the needed management support. Earthquake loss estimates are forecasts of damage as well as human and economics impacts that may result from future earthquakes. These estimates are based on current scientific and engineering knowledge. [9] The "earthquake loss estimation meth- 
odology" is a system that uses mathematical formulae and information about building stock, local geology and the location and size of earthquake risk, economic data and other information to estimate losses from a potential earthquake. The EIMS uses ArcGIS (geographical information system) to map and display ground shaking, the pattern of building damage and demographic information about a community. Once the location and size of a hypothetical earthquake are established, EIMS will estimate the distribution of the amounts of the following: ground shaking, buildings damaged, injured persons, damage to transportation systems, disruption of electrical and water utilities, displacement of populations and cost of repair of likely damage. [10-13]

\begin{tabular}{ccccc}
\hline \multicolumn{5}{c}{ Deadliest earthquake } \\
\hline Year & Date & Magnitude & Fatalities & Region \\
\hline 2005 & $03 / 28$ & 8.7 & 1313 & Northern Sumatra, Indonesia \\
\hline 2003 & $12 / 26$ & 9.0 & 283,106 & Off the west coast of Northern Sumatra \\
\hline 2002 & $03 / 25$ & 6.1 & 1000 & Southeastern Iran \\
\hline 2001 & $01 / 26$ & 7.7 & 20,023 & Southern Sumatera, Indonesia \\
\hline 2000 & $06 / 04$ & 7.9 & 103 & India \\
\hline 1999 & $08 / 17$ & 7.6 & 17,118 & Afghanistan-Tajikistan border region \\
\hline 1998 & $05 / 30$ & 6.6 & 4000 & Northern Iran \\
\hline 1997 & $05 / 10$ & 7.3 & 1572 & Yunnan, China \\
\hline 1996 & $02 / 03$ & 6.6 & 322 & Kobe, Japan \\
\hline 1995 & $01 / 16$ & 6.9 & 5530 &
\end{tabular}

Table 1. Deadliest earthquakes by year, 1995-2005

Estimation of losses from future earthquakes is essential for preparation for disasters and it facilitates better decision making at local, regional, provincial and national levels of government. An EIMS can estimate earthquake losses to support land-use planning and facility site decisions (e.g., a map-based analysis of the potential intensity of ground shaking from a postulated earthquake that identifies those parts of the community that will experience the most violent shaking and the buildings at greatest risk of damage); prioritization of retrofit or abatement programs (e.g., an estimate of building damage that provides the basis for establishing programs to mitigate or strengthen buildings that may collapse in earthquakes by providing estimates of damages and casualties); regional, provincial and local emergency response and contingency planning (e.g., estimates of casualties and of damage to buildings and utilities); medical and relief agency preparedness and response (e.g., estimates of casualties and homelessness); and assistance planning. [11] 
In this research, I seek to answer five important questions: When are EIMS useful? What are the essential substructures in an EIMS? What are the important functions of an EIMS? What are the steps taken to create an EIMS? and How is an EIMS used to prepare for earthquakes?

\section{Aim}

In this study, the information management networks related to earthquakes in India, Afghanistan, Japan, and Turkey were compared to Iran to rationally determine the relative strength of the EIMS in each country. Their weaknesses and strengths were determined. And several recommendations and a model were developed to eliminate weaknesses, improve the efficiency of EIMS, reduce damages and losses and expedite relief to victims after earthquakes.

\section{Methodology}

This research is empirical and the study was an analytical comparison. The data consisted of the population of EIMS employed in India, Afghanistan, Japan, and Turkey and Iran. These countries were chosen because they are among the countries with the most experience with extreme events in Asia, and they all experience devastating earthquakes (Table 1).

To perform this study, I developed forms and questionnaires for data collection through interviews and observations. The forms were developed to define standard characteristics of an information management system by extracting guidelines from the Joint Commission on Accreditation of Healthcare Organization (JCAHO), the American Health Information Management Association (AHIMA) and Canadian Council on Health Services Accreditation (CCHSA) [14] and synthesizing the information. The questionnaire was designed to acquire the opinions of experts to enable the weighting of each characteristic of an EIMS. In the first phase of data collection, the forms were validated and the questionnaire was approved. Internet sources, professional personnel, documents, journals and books were consulted to develop the data which included EI sources, methods of recording, storing, retrieving, analyzing, interpreting, and distributing EI, national and international usage of EI, and so on. The Criteria Rating Technique [15] and the descriptive method were used to analyze findings. Standard characteristics of information management systems were selected as criteria.

To compare the importance of the characteristics of EIMS, experts were asked to set weights (from 1, of low importance, to 10, of high importance) by brainstorm. The means of the experts' opinions of the weight of each criterion were calculated (Table 2 and 3). Ratings were established (ratio $=$ weight of each criteria divided by sum) and scales (positive $=4$, moderate $=3$, not access $=2$, negative $=1$ ) and scores (score $=$ ratio*scale) for selected countries were calculated. 


\begin{tabular}{|c|c|c|c|c|c|c|c|c|}
\hline \multirow[t]{2}{*}{ Criteria/country } & \multirow[t]{2}{*}{ Weight } & \multirow[t]{2}{*}{ Ratio } & \multicolumn{2}{|c|}{ India } & \multicolumn{2}{|c|}{ Afghanistan } & \multicolumn{2}{|c|}{ Iran } \\
\hline & & & Scale & Score & Scale & Score & Scale & Score \\
\hline 1) Information sources are existed & 8 & 0.11 & $\overline{4}$ & 0.44 & 4 & 0.44 & 3 & 0.33 \\
\hline 2) Users of El are specified & 6 & 0.08 & 4 & 0.32 & 3 & 0.24 & 3 & 0.24 \\
\hline 3) System has security process & 6 & 0.08 & 4 & 0.32 & 2 & 0.16 & 2 & 0.16 \\
\hline $\begin{array}{l}\text { 4) El is recorded and stored } \\
\text { systematically }\end{array}$ & 7 & 0.09 & 4 & 0.36 & 4 & 0.36 & 1 & 0.09 \\
\hline $\begin{array}{l}\text { 5) El is retrieved, analyzed and } \\
\text { interpreted systematically }\end{array}$ & 9 & 0.12 & 4 & 0.48 & 2 & 0.24 & 3 & 0.36 \\
\hline $\begin{array}{l}\text { 6) Administrators are specified in various } \\
\text { functions }\end{array}$ & & 0.12 & 4 & 0.48 & 4 & 0.48 & 3 & 0.36 \\
\hline $\begin{array}{l}\text { 7) No parallel and repeated activities by } \\
\text { various organizations }\end{array}$ & 5 & 0.07 & 4 & 0.28 & 4 & 0.28 & 1 & 0.07 \\
\hline $\begin{array}{l}\text { 8) El is distributed and used in national } \\
\text { and international levels }\end{array}$ & 6 & 0.08 & 4 & 0.32 & 4 & 0.32 & 3 & 0.24 \\
\hline 9) EIMS has feedback & 9 & 0.12 & 4 & 0.48 & 4 & 0.48 & 3 & 0.36 \\
\hline 10) Accessibility of El is easy and fast & 8 & 0.11 & 4 & 0.44 & 3 & 0.33 & 1 & 0.11 \\
\hline Sum & 73 & 1 & & 4 & & 3.3 & & 2.32 \\
\hline
\end{tabular}

Table 2. The EIMS characteristics evaluating in selected countries

\begin{tabular}{|c|c|c|c|c|c|c|c|c|}
\hline \multirow[t]{2}{*}{ Criteria/country } & \multirow[t]{2}{*}{ Weight } & \multirow[t]{2}{*}{ Ratio } & \multicolumn{2}{|c|}{ Japan } & \multirow{2}{*}{$\begin{array}{r}\text { Turkey } \\
\text { Scale }\end{array}$} & \multicolumn{3}{|c|}{ Iran } \\
\hline & & & Scale & Score & & Score & Scale & Score \\
\hline 1) Information sources are exist ed. & 8 & 0.11 & 4 & 0.44 & 4 & 0.44 & 3 & 0.33 \\
\hline 2) Users of E.I. are specified. & 6 & 0.08 & 4 & 0.33 & 4 & 0.33 & 3 & 0.25 \\
\hline 3) System has security process. & 6 & 0.08 & 2 & 0.16 & 4 & 0.33 & 2 & 0.16 \\
\hline $\begin{array}{l}\text { 4) E.I. is recorded and stored } \\
\text { systematically }\end{array}$ & 7 & 0.09 & 4 & 0.38 & 4 & 0.38 & 1 & 0.09 \\
\hline $\begin{array}{l}\text { 5) E.I. is retrieved, analyzed and } \\
\text { interpreted systematically. }\end{array}$ & 9 & 0.12 & 4 & 0.49 & 4 & 0.49 & 3 & 0.37 \\
\hline $\begin{array}{l}\text { 6) Administrators are specified in various } \\
\text { functions. }\end{array}$ & 9 & 0.12 & 4 & 0.49 & 4 & 0.49 & 3 & 0.37 \\
\hline $\begin{array}{l}\text { 7) No parallel and repeated activities by } \\
\text { various organizations. }\end{array}$ & 5 & 0.07 & 4 & 0.27 & 4 & 0.27 & 1 & 0.07 \\
\hline $\begin{array}{l}\text { 8) E.I. is distributed and used in national } \\
\& \text { international levels. }\end{array}$ & 6 & 0.08 & 4 & 0.33 & 4 & 0.33 & 3 & 0.25 \\
\hline 9) EIMS has feedback. & 9 & 0.12 & 4 & 0.44 & 4 & 0.49 & 3 & 0.37 \\
\hline 10) Accessibility of E.I. is easy and fast. & 8 & 0.11 & 4 & 0.44 & 4 & 0.44 & 1 & 0.11 \\
\hline Sum & 73 & 1 & & 3.77 & & 4 & & 2.37 \\
\hline
\end{tabular}

Earthquake Information= El; Ratio = weight of each criteria/sum; Score = ratio*scale

Scales: Positive $=4$, moderate $=3$, negative $=1$, not access $=2$

Range of ranks: 1-1.6: Very weak; 1.7-2.2: Weak; 2.3-2.8: Moderate; 2.9-3.4: Good; 3.5-4: Very good

Table 3. The EIMS characteristics evaluating in selected countries (continued) 


\section{Results}

The results of the data collection provide answers to the five research questions. Each answer is described briefly below.

When are EIMS useful? There are four conditions that make EIMS more useful: when information users and addressers are specified; when time, form and the mechanism of information distribution are specified; when the EI is valid and reliable; and when there is fast access to EI. Furthermore, the data received are often not helpful for management decision making because they are incomplete, inaccurate, untimely and unrelated to the priority tasks and functions of crisis management.

What are the essential sub-structures of an EIMS? The information compiled and surveys indicate that the essential sub-structures that must be addressed or included in an EIMS are the nature of: crisis management, information technology, the geographic information system, the earthquake information system, mass media communication, cell phone communication, capital and human resources.

What are the important functions of an EIMS? This study finds that EIMS are needed: for fast and easy retrieval of information, which is very difficult; for extraction and access of information for managers and related users; for integrating data from different sources; for reduction of parallel and redundant activities by responding organizations; to decrease cost and time; for assessment and monitoring of plans before and after earthquakes; to identify training and function needs; and to formulate prevention, action and rehabilitation actions.

What are the steps taken to create an EIMS? The following steps are usually taken: establish a joint commission of governmental and non-governmental sectors and organizations; determine the primary participants in earthquake management; determine and formulate a plan for a system based on general principles and goals; identify the data needed for the system; identify the sources for the system's informatics; identify registration, collection and storage methods of and administrators for the system; determine the retrieval and analytical methods of and administrators for the system; establish the information methods and distribute them to the administrators of the system; establish methods of systematic communication among the administrators; create a mechanism to render feedback for system improvement; and ensure that the system and its plans and functions are dynamic and flexible.

How is an EIMS used to prepare for earthquakes? The first step in preparing for a disaster is estimate and assess its potential impact. These estimations and assessment can provide the basis for developing mitigation policy, developing and testing emergency preparedness and responsing for post-disaster, and reliefing negative outcomes. [16] Reducing earthquake loss begins before the earthquake. Loss estimates provide public and private sector agencies with a basis for planning, zoning, building codes and development regulations, and policy that would reduce the risk posed by violent ground shaking and ground failure. Loss estimates can also be used to evaluate the cost-effectiveness of alternative approaches to strengthening potentially hazardous structures. Preparing to respond, understanding the scope and complexity of earthquake damage is essential to effective preparedness. The EIMS 
can forecast damage to buildings, casualties and disruption of utilities. These estimates can serve as the basis for developing emergency response plans and for organizing tests and exercises of response capability.

\section{About EIMS}

Beginning in the late 1950s, planners began development and use of computerized models, planning information systems and decision-support systems to improve EI management performance. They have found tools to enhance their analytical and geospatial technologies which may be different from one country to another. The industrialized nations are well adapted to this information technology. They use it in many fields. Governments apply urban information systems in all aspects of the planning process, including data collection, storage, data analysis and presentation, planning and policymaking, communication with the public, policy implementation and administration. The United States is the pioneer in this field. They began working with urban information systems in the 1970s. Canada and Australia have developed systems. And European countries like France, Germany and the Netherlands have been successful in applying these technologies. Turkey is a latecomer in this field because of financial constraints, their other priorities, a lack of technical expertise and different administrative mentalities. But today, the urban information system is a popular notion among local governments in Turkey. The first initiative of local governments to use urban information systems was in the cities Bursa and Ayden beginning in the mid-1990s. Since then three other metropolitan municipalities, Istanbul, Ankara and Izmir, studied the digitization of maps and plans and began to create inventories of their cities.

In India, findings showed that the Disaster Information Management System (DIMS) was launched by SRISTI. The SRISTI participated in relief and rehabilitation work in Kutch. However, their relief work suffered immensely due to lack of information and proper planning. When answers to important questions that were cropping up were needed - for instance, whether there is a database on the distribution of available resources and expertise with individuals, institutions and corporations - SRISTI discovered the information wasn't available. This revealed the need for a system for disaster mitigation and for documenting the experiences of individuals and organizations, which might provide a knowledge database that can assist coordination in future disasters. Thus, SRISTI initiated an effort to build a "Disaster Management Information System." Through this initiative, the development of a database-driven information system for Disaster Management Authorities (DMA) in various states, NGOs and other organizations is underway. SRISTI appealed to NGOs, relief workers, DMAs and individuals to share their experiences and volunteer their services and resources to the online database maintained on the SRISTI website. The database currently contains information from more than a thousand volunteers who have offered their services and resources in times of emergency. About 700 organizations and institutions are indexed on the site, as are other resources and web links. The DMIS is a voluntary activity run with in kind contributions of time and services by SRISTI volunteers, NGOs and, above all, civil 
institutions across the world. All the information shared with us is accessible to all, except in cases in which the volunteer has chosen to limit access to the relevant authorities. [17-18]

\section{EIMS in Afghanistan}

Our research reinforces the belief that Afghanistan possesses the potential for many natural disasters. Therefore, a DIMS, especially an EIMS, would be particularly helpful. Disaster management is a needs a wide variety of information, needs to track different locations and during different periods, and this information must have a set format in order that key staff can employ the information in decisions. A new project named "Management Information for Natural Disasters" (MIND) in Kabul and Kunduz provinces in Afghanistan has been operating since the beginning of 2012 and has been doing well for the last 8 months. Its goal was to establish and expand a crisis information management system. It is frequently updated and provides information to governments. MIND has increased Afghanistan's crisis management capacity nationally, supporting the training of disaster managers and improving city services by building governmental organizations in management information for natural disasters. Natural disaster management in these two provinces is primarily guided by estimates of damages which are used to direct rescue operations. There is currently no system to avoid or decrease disaster damages. Before and after a disaster, management is very weak in these countries and they are therefore dependent on the UN or NGOs for response. Information needed for the EIMS includes the availability and distribution of response personnel and spatial information stored in GIS to determine the areas of greatest destruction and locations of great danger. In this system, satellite data are crucial for identification of crisis locations and understanding their distribution. [17,19] To record the information that is acquired, an Information System Unit is trained to input data and information and to manage stations of the informative system. The DIMS for earthquakes has tended to not be useful in many parts of the country primarily because of the lack of timely information from disaster areas.

\section{EIMS in Japan}

The Japanese DIMS is called "PHOENIX" (Preement Hyogos Emergency Management Network for Disaster Information Exchange). [20] In this system, information about the amount and degree of earthquake damages and on-going developments of conditions in a disaster area are collected and processed. Information is provided by agencies, involved organizations, individuals (including those from governments, experts, volunteers and others), monitoring stations and other data sources employing several communication methods (including the Internet, radio, print, televison and satellite). Recording and collecting earthquake information is centralize by informatics centers of local society of province. Japan's Red Cross, Rescue Team, NGOs, health organizations and others [21] do the estimating, calculating, and publishing of the information that is needed, and they 
send them to the relevant agencies. PHOENIX crisis management is designed for access and use by individuals, local communities and the national government. All satellite, land-based and atmospheric data will be transmitted over the Internet and displayed on local pages for Hyogo people. This system has been established for the entirety of Japan. [20] The Hygo Province crisis management network is directly supervised by the prime minister and his/her ministry. According to their documents, this system has been very successful. So it is expected that after they have completed their analysis, the system will be on-line for local, national and international users. [20]

\section{EIMS in Turkey}

Our findings reveals that every governmental office in Turkey has begun development of electronic systems to meet their needs. Hence, e-government has become an important tool. As a result, the Turkish government has resolved to provide public services online in accordance with EU targets. As a part of this process, the prime ministry of Turkey has chosen Istanbul as a pilot-project area where many complex governmental tasks are carried out. Turkey is situated in an extremely active seismic zone. Since Istanbul has been growing rapidly without proper planning, great precautions should be taken to mitigate and prepare for future disasters. Therefore, Turkey has committed to build a natural disaster management information system immediately and it is called AFAYBIS. AFAYBIS is designed as a minor part of their e-Government system. It was based upon the information acquired in surveyes of government and private-sector data providers. The system will use geographical analysis to identify the regions with the greatest disaster potential. The project is also intended to quickly and effectively create a tool for management of response and relief during and after disasters. After an analysis of the current state of affairs was completed, the data and the data sources were identified. The system is designed as two parts: a database and a communication system. The communications component is to constantly update data before disasters and to provide continuous supply of data. Consequently this disaster information system is designed according to the standards of the Turkish e-government, which is always intended to be up-to-date. The disaster management information system that has been developed to solve this problem will result in optimum efficiency during disaster. This system contains the structure that determines its relationships to data and access to its information, disaster management communication, risk mitigation and disaster preparation, and postdisaster coordination of the prime minister, governors and other institutions. The services and duties of the institutions are also developed into the system so as to avoid modification of their existent organizational structures. [22] Earthquake management in Turkey, without exception, is a problem. It is unsystematic, unplanned, static and awareness of it is low.

\section{EIMS in Iran}

Disaster management systems are often designed because of the lack local management. Disasters are managed nationally in Iran and such management tends to cause disasters to 
spread, impacting many more people. [1] Despite the national approach, there is no official department called the "Department of Earthquake Information Management System." There is an EIMS. Information has been recorded by hand or using computers. Management of disasters has been done through the crisis office of the health ministry. All of the universities of Iran and the health minister are responsible for information management. This system is equipped to communicate information from crisis offices in the country's universities. After an earthquake, these units are prepared to produce up-to-date information (about hospitals, the Red Crescent Society, ambulances, facilities and other important resources) and report it to the crisis-control office. In universities, the crisis rooms are expected to report information as rapidly as possible. The EIMS in Iran tended to be incapable of reporting important information that was needed in advance of, during and after earthquakes. Defective, insufficient and inaccurate registration of data, declaration and publication of different and contradictory population data and a lack of reliable information disabled the development of preventative systemic planning. To make an EIMS work in Iran, we need to provide support for managers, and to do this, modified model of the EIMS should be designed. [1] The modified model includes information about: the responsible organizations, their functions, and the work-flow that were reflected in the Delphi Technique.

We offer a model that shows the relationships between organizations related to the EIMS in Iran (Figure 1). In this model, the responsibility and function of every organization is determined. These duties are classified according to registration and collection of earthquake data, the storage and processing of these data, and the analysis and distribution of information and recommendations produced by the EIMS.

\section{Evaluating the effectiveness of EIMS design in each country}

The highest sum of scores of the effectiveness of EIMS are found in India and the lowest in Iran (Table 2 and 3). The weaknesses of EIMS are found in that: the EI stores systematically, there are parallel and repeated activities by various organizations, and the access to the EI is not easy and nor fast, particularly in Iran's EIMS. In the range of ranks, Afghanistan's and India's systems were classified in the very good range and Iran's was in the moderate range. [17]

The use of mass media is imperative for communicating news and information to the public. Responsible journalism can also help to clear up inaccurate rumors and to influence the public's attitude toward preparing for disasters. Moreover, press coverage of old disasters may provide good data to fill the gaps in circumstances where official records do not exist. However, this study has revealed that the press has largely failed in terms of guidance toward disaster mitigation and preparedness. It seems that media are more interested in reporting disastrous news than informing the public of ways to avoid disasters. The Turkish media has been more influential in urging both the public and government officials to prepare for the earthquakes. Television appears to be a more effective tool to achieve this. [23] 


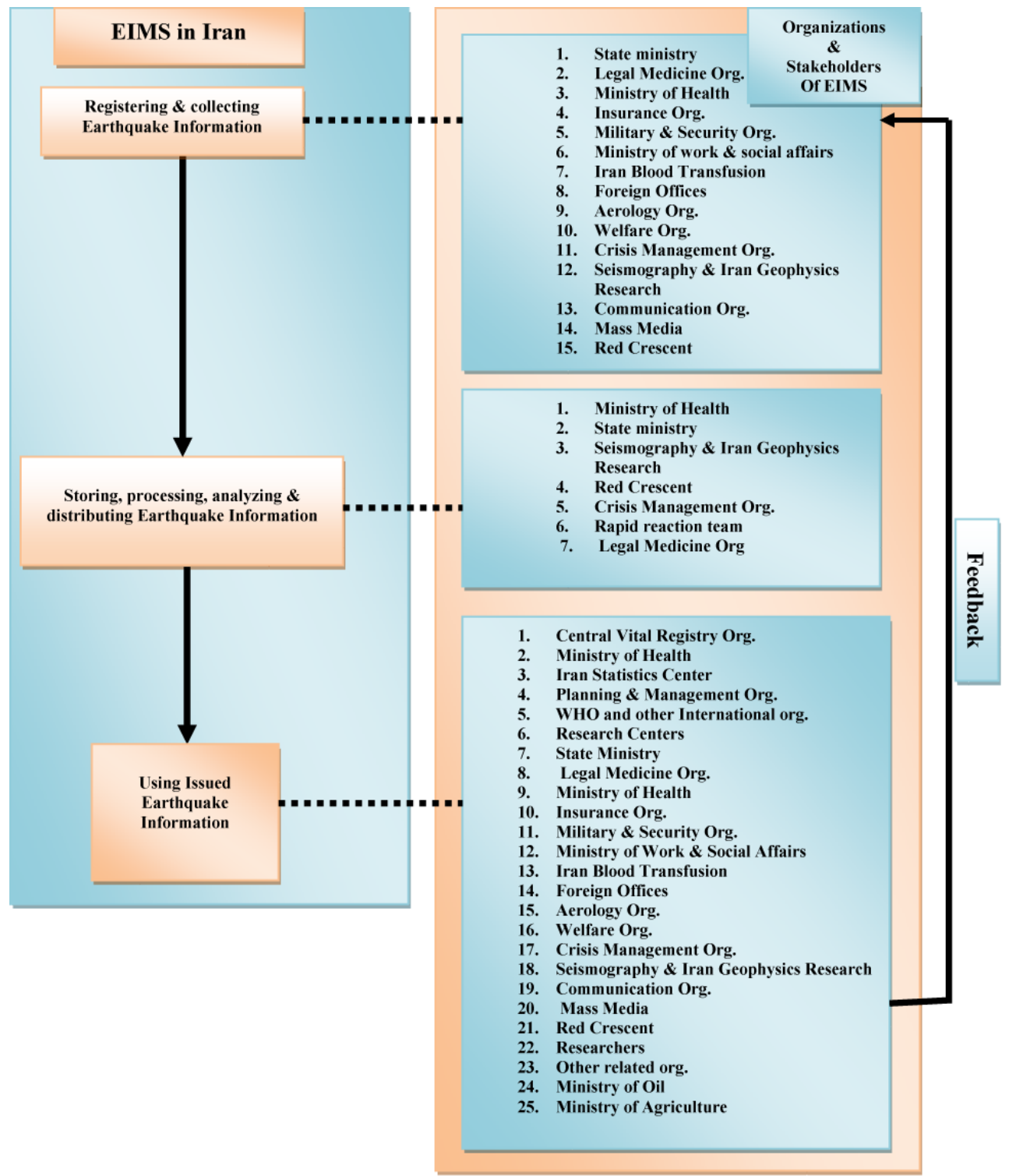

Figure 1. The proposed model of EIMS that shows process of relationships between organizations related to EIMS in Iran

The Japan Meteorological Agency (JMA) is responsible for producing EI and tsunami forecasts and they have developed an earthquake notification system in Japan. At present, JMA issues the following kinds of information successively when a large earthquake occurs: 
prompt reports of the occurrence of large earthquakes and major seismic intensities caused by earthquakes within about 2 minutes after the earthquake; tsunami forecasts in around 3 minutes; expected arrival times and maximum heights of tsunami waves in around 5 minutes; and location of the hypocenter and the magnitude of the earthquake, intensity at each observation station, times of high tides and the expected tsunami arrival times within 5-7 minutes. To issue the above information, JMA has established an advanced nationwide seismic network with about 180 stations for seismic-wave observation and about 3400 stations for instrumental seismic intensity observation, in addition to the approximately 2800 seismic intensity stations maintained by local governments. [24]

\section{Conclusion}

The initial effort to systematically collect and analyze data in developing countries should be undertaken by national program managers. Based on our investigation of current earthquake information management in India, Afghanistan and Iran, we can stress the need for further development of EIMS because of: the critical need for the information that must be gathered; a concern about continuous improvement of the data made available; its ability to help manage emergency response and relief in natural disasters (through more rapid availability and retrieval in an EI); a need for timely reporting and feedback to managers; the need to analyze information and render reports that define strengths, weaknesses, threats and opportunities; the need for monitoring the status of healthcare services and the needs of such services; the crucial need to coordinate activities between government and non-governmental sectors through the EIMS; the need to reduce deaths and establish health priorities and planning to decrease mortality after future earthquakes; the ability to use the outcomes of crisis to determine the causes of earthquake mortalities and other problems in order to prevent future impacts; and the need to formulate strategies for disease prevention and to reduce preventable deaths in earthquake zones.

A rapid response to a damaging earthquake will reduce the loss of life, lessen the complications that stem from injuries and secondary damage, and expedite relief to victims. Reliable and up-to-date information can have an impact on the mitigation of risk and prevention of disaster. Because of the financial and human costs of disasters, the establishment of a general, scientific and practical earthquake information management network is desperately needed.

\section{Acknowledgment}

The author would like to thank Misses Z. Moradi, Mahshid Fattahi and N. Nematolahi for helping to fulfill this research. 


\section{Author details}

Sima Ajami

Address all correspondence to: ajami@mng.mui.ac.ir

Department of Health Information Technology, Health Management and Economics Research Centre, School of Medical Management and Information Sciences, Isfahan University of Medical Sciences, Isfahan, Iran

\section{References}

[1] Bamdad N. The Role of Community Knowledge in Disaster Management: The Bam Earthquake Lesson in Iran. Institute of Management and Planning Studies, Tehran, Iran. Available from: http://www.engagingcommunities2005.org/abstracts/S93-bamdad-n.html/(accessed 11 September 2012).

[2] Tavakoli N. Health information management in disaster' proceeding of second national health and management disaster meeting, 2004 Nov 24-26, Tehran, Iran.

[3] Rastegari H, Ajami S. An overview of the management of a crisis. Health Information Management 2005;2(3):73-81. http://him.mui.ac.ir/index.php/him/article/view/28/26.

[4] Ajami S. The role of information management in rendering healthcare in disasters. In Proceeding of Second National Health and Management Disaster meeting, 2004 Nov 24-26, Tehran, Iran.

[5] The U.S. Geological Survey, Earthquake Hazards Program. Disaster Management Information System, fact sheet 04: Largest and Deadliest Earthquakes by Year 1990 2005'. Available from: http://www.sristi.org/dmis/facts.(accessed in 2009).

[6] Division of International Health, Department of Health and Human Services, Centers for Disease Control and Prevention, Epidemiology Program Office. Public Health Systems Development; Health Information Systems. [online]. United States. Available from: http:// www.cdc.gov/epo/dih/systems.html.(accessed in 2000).

[7] Seismological Bureau of Yunnan Province. Improvement of Earthquake disaster reduction and early warning systems. [online]. PR, China. Available from: http:// www.chinaproject.network. (accessed in 2001).

[8] Lippeveld T, Sauerborn R, Bodart C. Design and implementation of health information systems. Geneva, Switzerland: World Health Organization; 2000.

[9] Rock ML. Effective crisis management planning: Creating a collaborative framework [online]. Educ Treat Child J 2000;23(3):248-64. 
[10] Seeger MW, Sellnow TL, Ulmer RR. Communication and organizational crisis. USA:Praeger; (accessed 11 April 2006).

[11] Kabirzadeh A. Disease control and prevention after natural disaster. In Proceeding of Natural Health and Management of Disaster Meeting, 2003 May 27-29, Tehran, Iran. In Persian

[12] Ajami S, Fatahi M, Moradi Z, Nematolahi N. An analysis studies on Earthquake Information Management Systems (EIMS) in Japan, Afghanistan and Iran and proposing a suitable model for Iran. In Proceeding of International Disaster Reduction Conference (IDRC), From 27 August to first of September 2006, Switzerland, Davos.

[13] Ajami S, Fatahi M, Moradi Z. Reduce destroys and rule of Earthquake Information Systems the Comparative study in Turkey, Afghanistan and Iran. In Proceeding of International Disaster and Risk Conference IDRC, from August 25 to August 29, 2008, Switzerland, Davos.

[14] Ajami S, Tavakoli-Moghadam O. A Comparative Study on Health Information Management System with Standards in Ayatolah-Kashani Hospital in Isfahan, Iran. Health Information Management; 2006;1(3): 63-7. http://him.mui.ac.ir/ index.php/him/article/view/47.

[15] Chang R. Success through Teamwork: A Practical Guide to Interpersonal Team Dynamics (High-Performance Team Series) (Paperback). Homa-ye-Salamat 2006;2:63-5. [ in Persian].

[16] Ajami S, Fatahi M. The role of earthquake information management systems (EIMSs) in reducing destruction: A comparative study of Japan, Turkey and Iran. Disaster Prev Manag 2009; 18(2):150-61.

[17] Ajami S. A comparative study on Earthquake Information Management Systems (EIMS) in India, Afghanistan and Iran. Journal of Education and Health Promotion 2012;1:27.

[18] Society for Research \& Initiatives for Sustainable Technologies and Institutions Organization (SRISTI). Disaster Management Information System' [online]. Available from: http://www.sristi.org/dmis/dmi_system. (accessed in 2009).

[19] Afghanistan Information Management Service (AIMS) Project [United Nations Development Program (UNDP)]. Information Management for Natural Disasters: Pilot Project for Kabul \& Kunduz Province. 2005, Kabul and Kunduz Province. Afghanistan. Available from: http:// www.aims.org.af/services/sectoral/d_m/ dmis_for_afg_a_p_p.pdf.(accessed in 2005).

[20] International Strategy for Disaster Reduction.Hyogo Framework for Action 2005-2015: Building the Resilience of Nations and Communities to Disasters. Extract from the final report of the World Conference on Disaster Reduction, 18-22 January 2005, Kobe, Hyogo, Japan. 
[21] International Strategy for Disaster Reduction.Hyogo Declaration. In proceeding of Conference on Disaster Reduction in Japan on 18_22 January 2005, Extract from the final report of the World Conference on Disaster Reduction, 18-22 January 2005, Kobe, Hyogo, Japan.

[22] Eraslan C, Alkis Z, Emem O, Helvac C, Batuk F, Gümüsay U. et al. System Design of Disaster Management Information System in Turkey as a Part of E-Goverment. Istanbul, Turkey: Department of Geodesy and Photogrammetry; 2004. http://www.cartesia.org/geodoc/isprs2004/comm2/papers/139.pdf.

[23] Dedeoglu N. Role of the Turkish news media in disaster preparedness. In Proceeding of International Disaster Reduction Conference (IDRC), From August 25 to August 29, 2008. Switzerland, Davos.

[24] Doi K, Kato T. Real time Earthquake information system in Japan. American Geophysical Union, Fall Meeting; 2003. Abstract \# S21B-03-12/2003.

[25] Yaliner O. Description of Urban information system and emergency management concepts, examples in Turkey and in the World. In Partial Fulfillment of the Requirements for the Degree of Master of Science in the Department of Geodetic and Geographic Information Technologies a Thesis Submitted to the Graduate School of Natural and Applied Sciences of the Middle East Technical University, January 2002. 